\title{
MODELING URBAN DYNAMICS: THE CASE OF PERIURBAN DEVELOPMENT IN EAST THESSALONIKI
}

\author{
GEORGIA POZOUKIDOU*
}

\begin{abstract}
School of Spatial Planning and Development, Aristotle University of Thessaloniki, University campus, Faculty of Engineering, 54124 Thessaloniki, Greece

* Corresponding author: gpozoukid@plandevel.auth.gr
\end{abstract}

\section{ABSTRACT}

\begin{abstract}
Understanding cities and their development is a complex and multifaceted issue. Cities are places where individuals, households, companies etc. concentrate to benefit from the agglomeration and proximity of urban activities. There are many ways to approach the critical question of how urban activities are spatially organized and interrelated to produce space and create cities. Recently a great number of complex systems were developed as part of the complexity theory approach in order to study urban dynamics, while mathematical models are seen as a new opportunity to explore the spatial relations via new evolutionary approaches.

Taking into consideration that the world is complex and no model can incorporate all the possible factors that cause urban growth we focus on the dynamics of land use and transportaiton infrastructure using a simple urban model for the periurban area of east Thessaloniki. Given the fact that there are no records of such models being used in studies of Greek cities over the last 25 years, makes this an important contribution to the use of models in a greek setting. Therefore, an applicability assessment of the model for the three different modelling steps (data acquisition, calibration and forecasting) is conducted. The application of the model indicates that despite issues about the availability of data, the calibration and forecasting results are promising for the use of urban models in greek cities. Furthermore it highlights the significance of using quantitative methods for understanding cities as systems, which in turn will enable us to make better planning decisions about our cities in the future.
\end{abstract}

Keywords: complexity; land use models; Thessaloniki; urban dynamics

\section{Introduction}

Understanding cities and their development is a complex and multifaceted issue. Cities are places where individuals, households, companies etc., concentrate to benefit from the agglomeration and proximity of urban activities. From a systemic point of view urban activities are organized at different scales (neighborhood, city, metropolitan etc.) and are interrelated in various aspects.

There are many ways to approach the critical question of how urban activities are organized and interrelated to create cities and their spatial configuration. The answer is neither simple nor obvious. Some try to explain cities' spatial configuration using principles like the continuation of historical development and land quality (i.e. suitability and attractiveness) while others explore public policies and the interactions of the interdependent components of the city (Schrojenstein et al. 2011). No matter the approach used to understand the evolution of urban systems the practical implication is that it is important to measure and understand the drivers of urban growth across the entire social system (Balmaceda et al. 2017). Therefore, urban planning must be informed of the state of art of our scientific knowledge through a highly and substantially interdisciplinary approach.

Recently many complex systems have been developed as part of the complexity theory approach used to study urban dynamics. Proponents of complexity theory and the evolutionary approach argue that spatial planning should reinvent itself to serve the new challenges of an urbanized world, and of which new techniques of data collection, mining, management and pattern recognition should be a part (Batty 2012).

In the context of this new paradigm for city science, there is a quest for complex systems. According to Boccara essential properties of such systems include a large number of components interacting via simple rules that are not centrally cotrolled, as in a self organized system (Boccara 2010). Furthermore, the conversation of the characteristcs of complex systems and the mathematical models that portray them, evolves around the concept of non linearity and the multiplicity of states that a system can achieve. Allong these lines Geoffrey West, coordinator of big projects on the new science of cities, thinks that collecting and analyzing big data sets could help us discover the laws of evolution of urban phenomena (TED Global Talk 2011). He also emphasizes the fact that the use of advanced mathematics to understand cities does not necessarily contradict the view of cities as a set of complex semi-autonomous and interdependent components and processes. Therefore, mathematical models should be seen as a new opportunity to explore spatial relations that include new evolutionary approaches that depend on the availability of massive data sets, in most cases real data that reflects human behaviour (Batty 2012).

In terms of the discourse on the new science of cities, this paper focuses on the use of mathematical models to depict urban dynamics. Taking into consideration that the world is complex and no model can incorporate all the possible factors that cause urban growth we assume that any model selectively focuses on a specific aspect 
and depicts a simplification of urban dynamics. Thus, this paper focuses on the dynamics of land use and transport infrastructure using a simple urban model for the periurban area of east Thessaloniki. Practical issues associated with the availability of data, calibration results and forecasting procedures are explored.

\section{Modelling Urban Dynamics}

Modelling urban dynamics presupposes an understanding of cities as a system of networks and flows. Therefore, in order to interpret space we must comprehend how flows and networks function as one system. Critical elements that define urban dynamics are the size of cities, their internal order, transport routes and the location of their activities (Batty 2013).

The location of specific activities illustrate the spatial organization of the network of socio-economic activities. Furthermore, the transport system connects the various activities and land uses by overcoming their physical separation, but at the same time increases mobility and accessibility, which may create new time-space relationships between land-uses (Rodrigue 2013). In addition, transport infrastructure occupies a significant part of the available space, especially in urban areas and may result in fragmentation and segregation effects (Seiler and Folkenson 2006; EC 2013).

Simulation models that correspond to this approach are the spatial interaction models. The first generation of these models were static synthetic economic and spa- tial interaction models. Their theoretical background is related to the science of regional economics, locational theories and urban economics. Thus, they embody the principle of land suitability, as a result of the interaction between factors determining economic production. From a mathematical point of view choice of location is determined by exponential or logarithmic models based on the method of utility maximization and entropy or random utility by setting limitations to the cost of transport, which in most cases is determined by income. These mathematical models calculate the probability of occurrence and establishment of an urban activity taking into account all the factors mentioned above (transport, rent, etc.). They incorporate the standard four-stage transportation modelling process consisting of trip generation, trip distribution, modal split and modal assignment and therefore are very suitable for an integrated land use transport approach.

In this paper, the TELUM-Transportation Economic Land Use Model (http://www.telus-national.org/products /telum.htm) is used to study urban dynamics in the periurban area of Thessaloniki. TELUM is a land use transport interaction model that attempts to replicate how networks, activities, population and flows are interrelated within an urban system. More specifically, TELUM attempts to replicate the interactions of the city's components (households, employers, developers and government) and record their consequences in a systematic way. It does not explicitly model every interaction, but it views them from an aggregative perspective. It focuses on how employment and its location affect the future location of

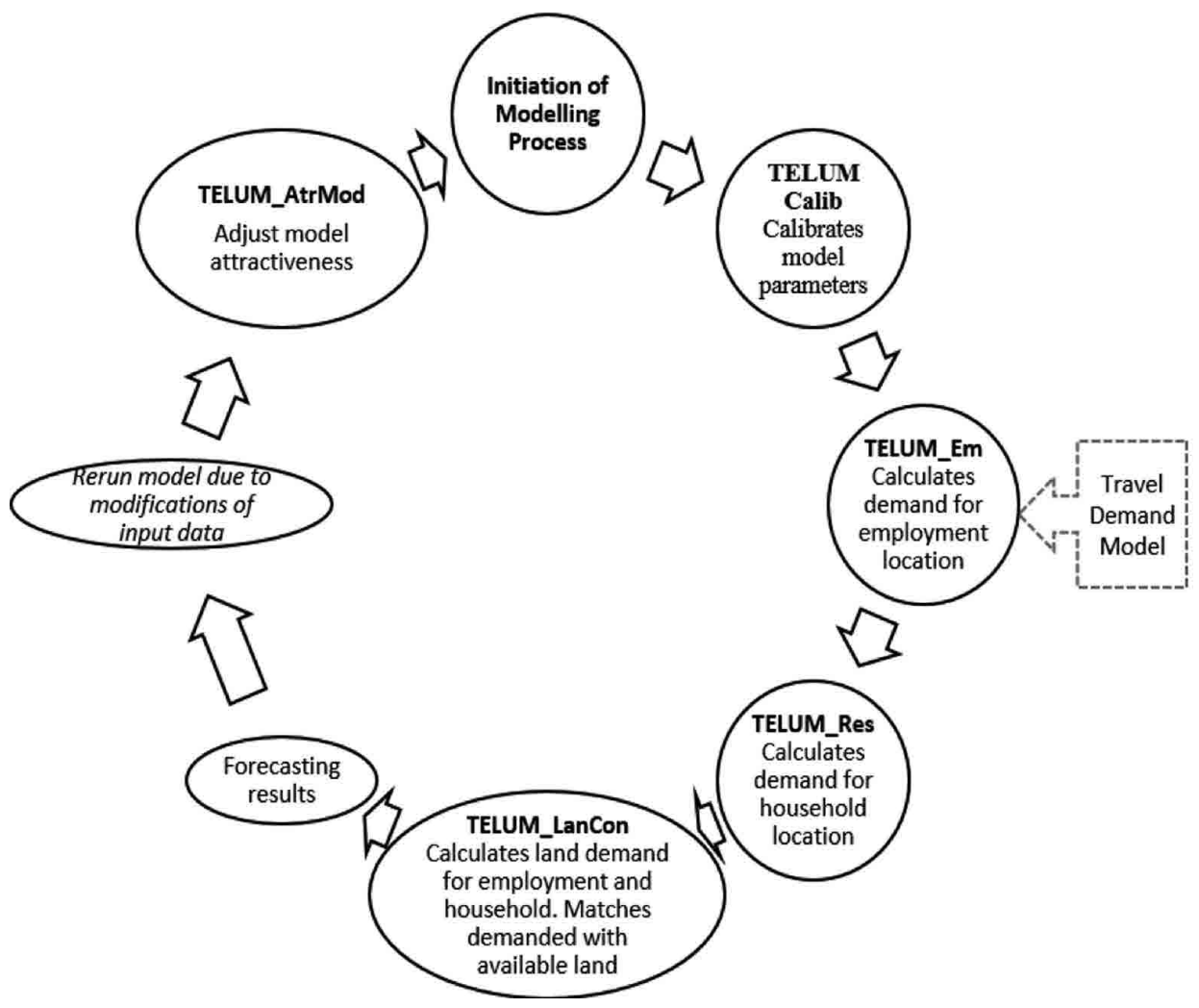

Fig. 1 Structure of the TELUM model. 
households, and in turn, the implications for the land-use development patterns in the region.

From a functional perspective, the modelling process in TELUM starts with the calibration of the model parameters for both the employment and residential allocation models (Fig. 1). It continues with forecasting employment and household growth and calculation of the associated demand for land. Based on the demand for land forecast, the system estimates the changes in the different types of land use (i.e. land for tertiary employment, high income households etc). If the user desires to make any changes in the forecasts produced by the model, i.e. incorporate local knowledge into the system, this can be done by adjusting the attractiveness of certain types of land use (Putman 2005).

\section{The Case Study of East Thessaloniki}

Greece does not have any tradition or experience of using predictive methods for land use planning and recording urban dynamics, a practice that has been quite commonly used in most west European and U.S. cities since the early 1960s. Therefore, simulation models have not been used to capture land use dynamics in the city of Thessaloniki. In general it was not until 1980 for Athens and 1997 for Thessaloniki that the first study of transport was conducted, when both cities had already experienced rapid suburbanization. To be more specific in the case of Thessaloniki this was the first and only time that such a study was ever performed. Nevertheless because of the extensive acquisition of mobility, demographic and land use data this was a high quality study.

Located in the eastern part of Thessaloniki's greater urban agglomeration the study area consisted of two municipalities, the Municipality of Kalamaria and that of Pylaia (Fig. 2a). The city (urban agglomeration) of Thessaloniki is the second largest city in Greece (after Athens), and one of the largest urban centers in the Balkans. Since the early ' 80 s the greater area of Thessaloniki experienced tremendous changes in terms of its morphological and functional organization. Key developments were a rapid urban expansion and formation of a "new city" that lacked defined boundaries and a center(s). New high-speed freeways (in conjunction with no investments in public transport), shopping centres, research and development (R\&D) facilities and companies' headquarters were scattered in the peri-urban area. At the same time, suburban housing became accessible and affordable for middle and low-income families, increasing housing demand and therefore becoming the main form of residential development.

The two municipalities studied were part of the urban expansion. To be more specific from 1991 to 2011 the Municipality of Pylaia experienced a tremendous increase in population (51\%) while the rest of the urban system either experienced a decline or no significant change. Main reason for this was the spatial proximity of Pylaia to Thessaloniki's dense urban area and the presence there of an attractive environment for household relocation due to a low residential density (mean floor area ratio 0.9) and presence of a natural environment. Except for the planned, mainly residential areas, Pylaia also had extensive areas that didn't have a designated land use so that practically any activity could be located there. This is a peculiarity of the Greek planning legislation, according to which any peri-urban, ex urban and rural area is potentially developable land (for residential, commercial etc. uses). In addition, this was the area that most of the new shopping centres, R\&D facilities and company headquarters were located due to the large amount of available developable land and its proximity to the airport and city of Thessaloniki (Fig. 2b).

On the other hand the municipality of Kalamaria had a quite different urban development profile since its whole area is part of the dense urban area of Thessaloniki. This municiplaity did not experience dramatic population changes over the last three decades due to the fact that this area had been under development for many decades. With a mean floor area ration of 2.9 it has a quite dense urban environment that was almost $100 \%$ fully developed. It is also primarily a residential area with the exception of certain central axes where facilites for recreation and providing services were developed.

\section{Data Availability and Acquisition}

Acquiring appropriate data for the model, is probably the most difficult, time consuming and tedious task in the modelling process. TELUM requires five types of data: population, employment, households, travel cost and land uses. Table 1 presents the type of data required to run all the modelling steps, along with their spatial and temporal reference. Souce of data used to run the model is also denoted.

Table 1 TELUM Basic Data Requirements.

\begin{tabular}{|l|c|c|c|}
\hline Type of Data & $\begin{array}{c}\text { Spatial } \\
\text { Reference }\end{array}$ & $\begin{array}{c}\text { Temporal } \\
\text { Reference }\end{array}$ & Source \\
\hline Population control totals & $\begin{array}{c}\text { Regional/ } \\
\text { TAZ }\end{array}$ & Lag-1991 & Census \\
\hline $\begin{array}{l}\text { Employment control totals } \\
\text { by sector }\end{array}$ & $\begin{array}{c}\text { Regional/ } \\
\text { TAZ }\end{array}$ & Lag-1991 & Census \\
\hline Households by income & TAZ & Current-1997 & TS \\
\hline Employment by sector & TAZ & Current-1997 & TS \\
\hline Interzonal travel cost & TAZ & Current-1997 & TS \\
\hline Land use (Total and by type) & TAZ & Current-1997 & TS \\
\hline $\begin{array}{l}\text { Average number of employ- } \\
\text { ees by household type }\end{array}$ & TAZ & Current-1997 & $\begin{array}{c}\text { Uniform } \\
\text { dist }\end{array}$ \\
\hline $\begin{array}{l}\text { Households (by income) per } \\
\text { employees (by sector) }\end{array}$ & TAZ & Current-1997 & $\begin{array}{c}\text { Uniform } \\
\text { dist }\end{array}$ \\
\hline $\begin{array}{l}\text { Regional rate of employee } \\
\text { commutation }\end{array}$ & Regional & Current-1997 & $\begin{array}{c}\text { Default } \\
\text { value }\end{array}$ \\
\hline
\end{tabular}



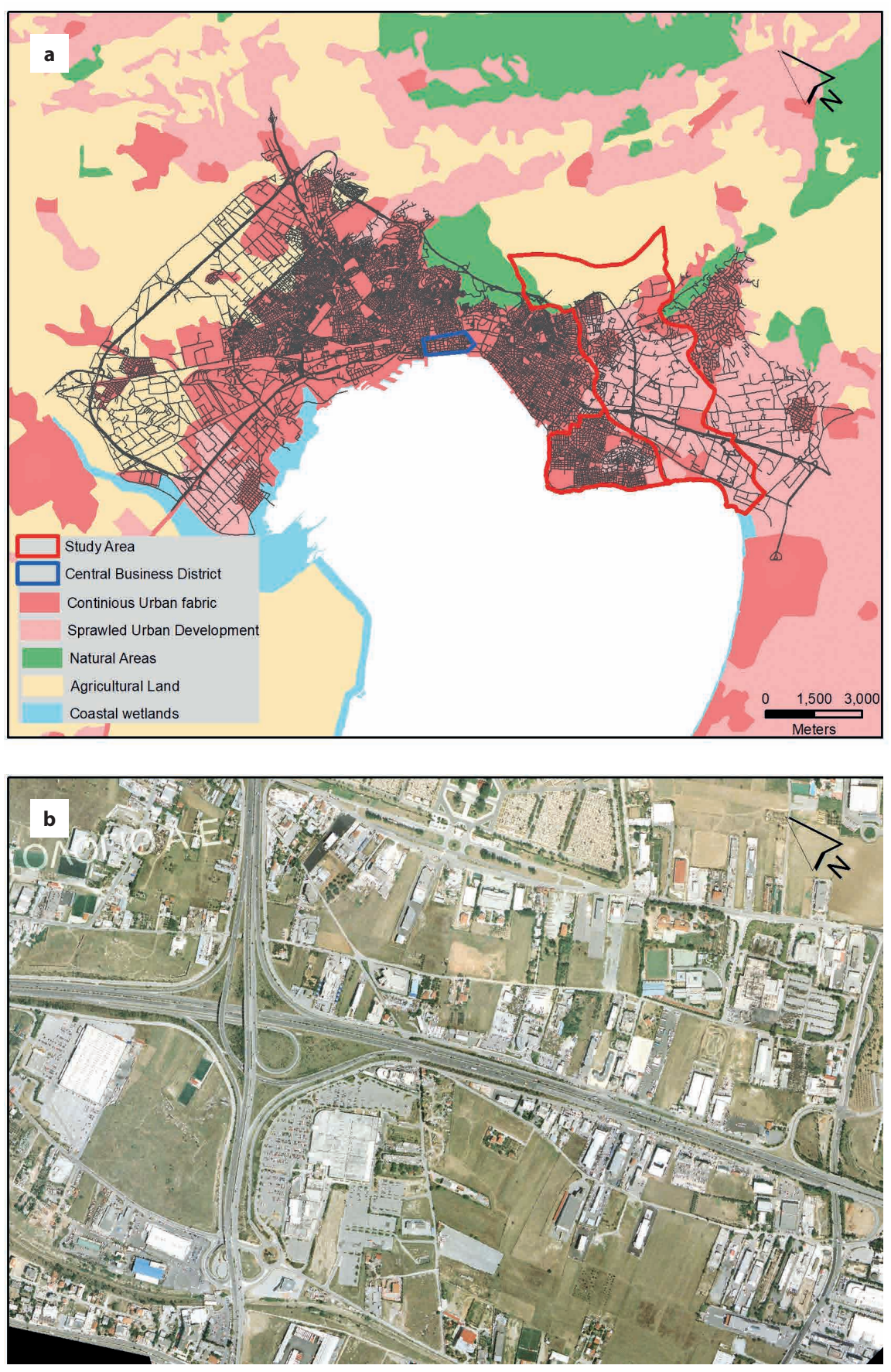

Fig. 2 (a) Location of the study area in the city of Thessaloniki (b) Big Box and R\&D development, National Cadastre and Mapping Agency S.A.

In terms of the data's temporal reference, it is predetermined since there is only data on transport for 1997, it is inevitable to set 1997 as the "current year" for the calibration and forecasting purposes. Therefore 1991, which is the preceding census year, becomes the "lag year". This results in a six year time interval, which is close enough to the five years that is considered to be the ideal time interval for modelling purposes. Fortunately employment, household and land use data are available in the 1997 study on transport. In terms of spatial reference Transportation Analysis Zones (TAZ) were used for most of the required data since this was the only spatial level for which such data was available for carrying out the calibration process. It was also the only spatial level for which there was data for employment by sector at the place-ofwork and not the place-of-residence (Pozoukidou 2014).

In terms of the land use data five different land use categories for each analysis zone is required. The categories are: total zonal area (study area), residential area (by household type), commercial area (used for commercial and third sector employment), industrial area, unusable area (e.g. water, environmentally sensitive lands, land with developmental constraints), and vacant developable area. Finally transportation data (zone to zone travel time, travel costs or a composite of both) were also necessary. Most of the required data were available in the transportation study but extensive readjustments had to be done in order to match the available with the trans- 
portation study data to provide data required for the TELUM (Zarov 2016).

\section{The Modelling Process}

The 40 TAZ includes the study area with a population of 130,000 inhabitants (1997 estimation). The four basic employment sectors used for the modelling process were a) "Basic" including primary and secondary sector employment, b) "Retail services" including employment in retail services (wholesale included), c) "Public services" including public services but also private provided services such as health, education etc. and d) "Advanced services" that includes finance, consulting, engineers, lawyers etc. All employment data were calculated at place-ofwork per TAZ for 1991 and 1997. In terms of household data four income based household types were designated. These were "low income", "middle income", "upper middle income" and "high income" per TAZ for 1991 and 1997. In terms of land use data five land use categories were used for each analysis zone, as described earlier.

All these data along with that on transport were entered into the "Data Organization and Preparation Unit" of TELUM. In this module TELUM performs a data consistency check in order to evaluate the quality of imported data. Results indicated high correlations between different pairs of data. More specifically, total current households and total lag households are closely correlated. The same applies for the four employment sectors. A high correlation between lag and current employment, in any employment sector (i.e. in "Basic" sector), indicates little or no change in the locational behaviour of that specific type of employment. Practically these data inconsistencies derive from the fact that both of the sets of employment data for 1991 was "constructed" in order to fit the model requirements, since there was no suitable data in the respective Census counts. In any case these types of data inconsistencies affect the validity of results and the respective variables should be replaced as more reliable data becomes available.

The next step in the modelling process is the calibration of the models embedded in TELUM. In specific terms calibration is the process of fitting the residential and employment models into the real world by estimating the parameters for each locator type (i.e. high income households, basic sector etc), which will be used in the models' equations. These parameters will be the ones that best fit the general model structure of the dataset and minimize the discrepancies between the model results and real data.

One of the first measures used for the best fit analysis is the Best/Worst Likelihood Ratio (B/W LR), which is a normalized maximum likelihood criterion. B/W LR is analogous to the $\mathrm{R}^{2}$ measure but more appropriate for the nonlinear equations of TELUM and non-normal distributions of the data. Another set of goodness-of-fit meas- ures examines the distribution of residuals (or errors) between the observed data and the models' current best-fit estimates. For this the Mean Absolute Percent Error, or MAPE, is commonly used. This is the average (mean) of the absolute values of percentage error between an observed set of say, household data and the values estimated by TELUM. Unfortunately, the value of MAPE can be easily distorted by large percentage errors in small zones. For example, if a zone with an observed ten households is estimated to have fifteen, it is a $50 \%$ error. If a second zone with 1000 observed households is estimated to have 1050 , it is a $5 \%$ error. The value of MAPE for these two zones taken together is $27.5 \%$, a value that exaggerates the forecast error of the model. One way to deal with this bias is to state the value of MAPE for just the smallest and largest observations (zones) in the data set along with the MAPE for all the zones taken together. In that comparison, we might see a MAPE of $500 \%$ in the smallest zones (which account for $2 \%$ of the region's low-income households) and a MAPE of $12 \%$ for the largest zones (which account for $87 \%$ of the region's low-income households). The MARMO measure is another way to give error measures that are weighted by the size of the observation and is a good summary measure of likely errors in forecasts. The best, and unachievable, value for MARMO is 0.0 , which would indicate a perfect fit of model to data. Normal values of MARMO vary from 10.0 to 40.0 for each locator type. The measures of goodness of fit based on the calibration process were quite satisfactory. Table 2 shows a summary of the calibration results for employment, where the three goodness-of-fit indicators are presented with their values. The B/W LR for the four employment sectors are high indicating that employment data fits very well the employment model. At the same time the MAPE values are quite low indicating that the estimated parameters for the employment model equation are the best-fit since the percentage of error between observed and model's current best fit estimates, for each one of the locator types, are within the acceptable range. The MARMO values are also acceptable.

Table 2 Employment Goodness of Fit.

\begin{tabular}{|l|c|c|c|}
\hline Employment Sector & B/W LR & MAPE & MARMO \\
\hline Basic & 0.9950 & $9 \%$ & $8 \%$ \\
\hline Retail & 0.9763 & $36 \%$ & $31 \%$ \\
\hline Public services & 0.9961 & $18 \%$ & $18 \%$ \\
\hline Advanced services & 0.9334 & $23 \%$ & $23 \%$ \\
\hline
\end{tabular}

Table 3 Household Goodness of Fit.

\begin{tabular}{|l|c|c|c|}
\hline Household Cat. & B/W LR & MAPE & MARMO \\
\hline low income & 0.9421 & $84 \%$ & $16 \%$ \\
\hline middle income & 0.9762 & $44 \%$ & $15 \%$ \\
\hline upper middle income & 0.9094 & $34 \%$ & $19 \%$ \\
\hline upper income & 0.8432 & $40 \%$ & $29 \%$ \\
\hline
\end{tabular}


For households, the B/W LR results are high indicating that the household data fit the household model (Table 3). At the same time MAPE values are at the high end of the acceptable range indicating that the estimated parameters for the respective model equations are not the best-fit model since the percentage of error between observed and the model's current best fit estimates for each one of the locator types are at the high end of the acceptable range. MARMO values are acceptable.

Proceeding to the calibration of the land consumption model it seems that the overall goodness of fit of the model for all household types and "Basic" employment sector is $73 \%$ and $69 \%$, respectively, indicating that the model can account for the majority of the zonal variation in the change in the use of land for housing and industry but cannot be a good predictor of it. On the contrary for retail, public services and advanced services the equation can account for most of the zonal variation (85\%) in land use and can be used to make reliable predictions of these types of land use.

The last step in the modelling process is forecasting spatial allocation for employment and households in the study area. In order to do this it is essential to have the future (forecast) travel impedance. Since this was not
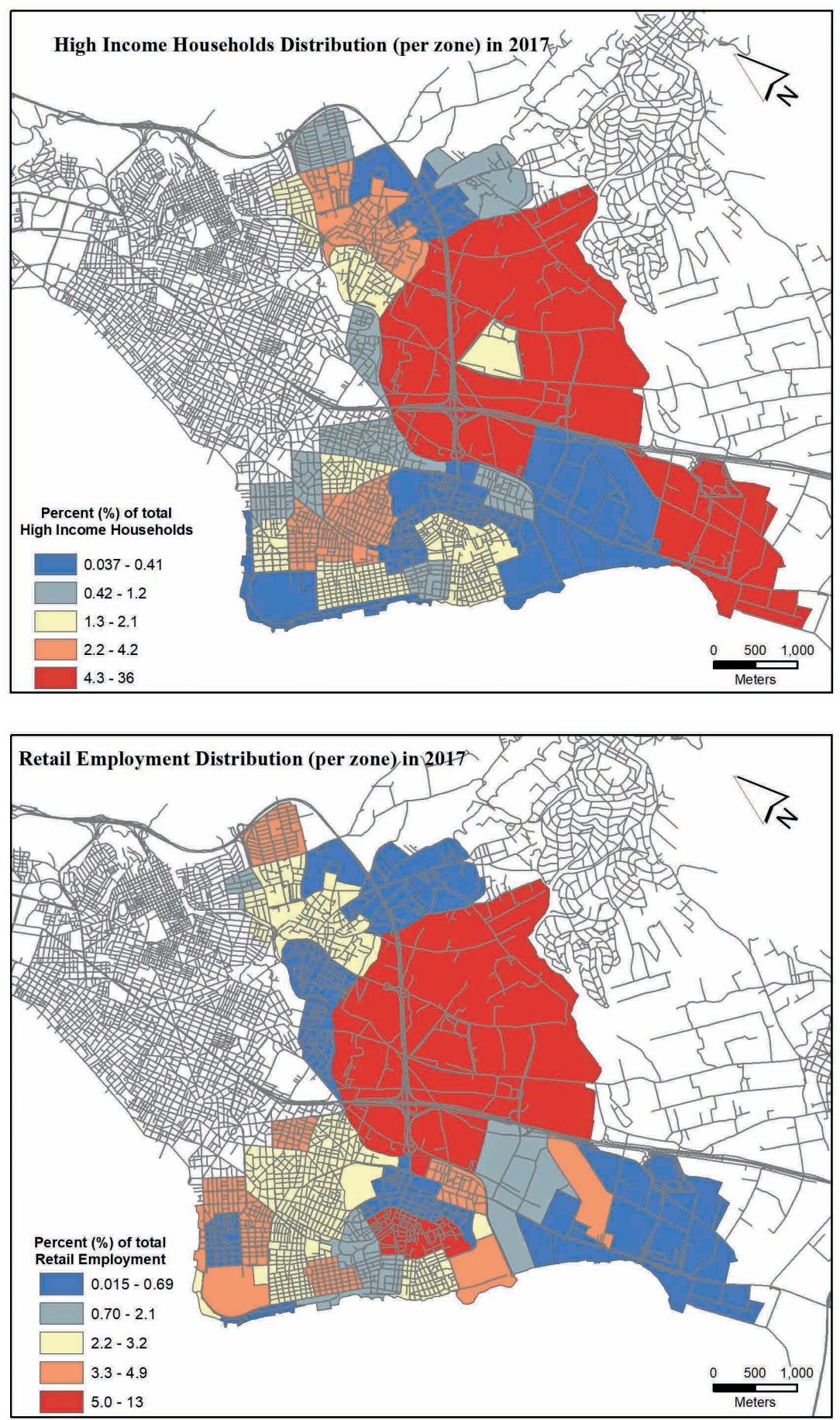

Fig. 3 Forecasts for high income households and retail employment in 2017. 
possible a baseline scenario was developed. In this scenario it is assumed that there will be no change in transport infrastructure, therefore, forecasts will be based on an observed level of activity, and calibrated attractiveness variables are obtained from the current year's data (travel impedance). The current year for the baseline scenario is 1997 and four 5-year time intervals were set for forecasting purposes (1997-2002, 2002-2007, 2007-2012, 2012-2017). Finally forecasting was also based on the future regional employment and household projections that were imported earlier into the system.

According to the forecasts there will be a $24 \%$ decline in the study area in the basic employment sector, while retail, public services and advanced services will increase by $25 \%, 4 \%$ and $4 \%$, respectively. In terms of households an increase of $10-14 \%$ for all four household types was recorded. In general, as expected, the model predicted an increase in population and household numbers as well as in the numbers employed in the tertiary sector. It is not possible to present the spatial distribution for each locator type and thus only a sample of the TELUM's outputs for the 2012-2017 forecasting period are depicted in the maps (Fig. 3). It is interesting to note that the model predicted an allocation of retail employment mainly at the fringe of the dense urban area, along the two main road axes, which gradually decreases as we move further south.

\section{Conclusions: Simple Models for a Complex World}

Production of urban space is neither a simple or an easy proccess to comprehend. It requires an understanding of the dynamics of an urban system and the complex procedures required for city growth. Attemps to model urban dynamics have led to extremely complex models, which attempt to consider the multiple interactions within an urban system. To this end various mathematical models have been developed using basic notions of complexity theory and have evolved around the concept of non linearity and multiplicity of states that a system can achieve.

This paper views mathematical models as a new opportunity to explore spatial relations, which include new evolutionary approaches. Taking into consideration that the world is complex and no model can incorporate all the possible factors that cause urban growth, we accept that models selectivelly focus on a specific aspect of urban dynamics. Along these lines this paper focuses on a specific aspect of urban development that incorporates the interaction between land use and transport infrastructure. A simple urban model for the periurban area of east Thessaloniki is used to record practical issues related to data availability, calibration and forecasting procedures.

Given the fact that there are no records of such models being used for the planning of Greek cities over last
25 years, makes this paper a critical contribution that supports the use of models in a Greek setting. Applicability assessment of the model was made for the three different modelling steps, i.e. data acquisition, calibration and forecasting, and the issues of data availability and standardization.

In particular, the data available for Thessaloniki lacked appropriate spatial and temporal references. The inevitable choice of TAZs as analysis zones created several problems in terms of obtaining appropriate data for the model, especially that related to employment at the place-of-work and land use. Despite data inconsistencies, calibration results indicated that employment, household and land use allocation models can account for most of the zonal variation in each locator type and can make reliable predictions. In an effort to highlight the usefulness of land use models as policy evaluation and decision making tools a future development scenario was also attempted. The available dataset enabled us to predict land use changes from 1997 to 2017 in 5 year increments. Results were comparable to the existing situation in 2017 indicating that despite the lack of data and certain assumptions the embedded models are suitable for use in Greek cities.

Finally, application of TELUM highlighted the importance of using urban models for planning, even using imperfect data, since it is important to understand the undelying interrelations within urban systems, which in turn will enable us to make better planning decisions about the future of our cities.

\section{REFERENCES}

Balmaceda B, Fuentes M (2016) Cities and methods from complexity science. J Syst Sci COMPLEX 29: 1177-1186.

Batty M (2012) Building a science of cities. Cities 29: 9-16.

Boccara N (2010) Modeling complex systems. Springer, Science \& Business Media.

European Commission (2013) A concept for sustainable urban mobility plans. Annex to the Communication from the Commission to the European Parliament, the Council, the European Economic and Social Committee and the Committee of the Regions: "Together towards competitive and resource-efficient urban mobility". European Commission, Brussels. https:// ec.europa.eu/transport/sites/transport/files/themes/urban/doc /ump/com\%282013\%29913-annex_en.pdf. Accessed 25 November 2017

GeoffreyW(2011)Thesurprisingmathofcitiesandcorporations.TED Global 2011. https://www.ted.com/talks/ggeoffrey_west_the _surprising_math_of_cities_and_corporations. Accessed 9 February 2017.

McLoughlin B (1969) Urban and regional planning: a systems approach. Faber and Faber.

Pozoukidou G (2014) Land use transport interaction models: Application perspectives for the city of Thessaloniki. Spatium 32: 7-14.

Putman S (2005) User Manual: TELUM Transportation Economic Land Use Model, Version 5. http:/wwww.telus-national.org /products/telumusermanual.pdf. Accessed 9 February 2017. 
Rodrigue JP (2013) The geography of transport systems (3rd Edition). Routledge Press, New York.

Schrojenstein Lantman J, Verburg P H, Bregt A, Geertman S (2011) Core principles and concepts in land-use modelling: A literature review. Land-use modelling in planning practice: $35-57$.
Seiler A, Folkeson L (2006) Habitat fragmentation due to transportation infrastructure. COST 341 Swedish national state-of-theart report. VTI publishing Linkoping.

Zarov P (2016) Land Use Modeling - From Theory to Practice. Application of TELUM Model in Eastern Thessaloniki, Diploma Thesis, Aristotle University Depository, Thessaloniki. 